\title{
Maxillo-facial radiology case 151
}

SADJ June 2017, Vol 72 no 5 p227

CJ Nortjé

Below is a clinical picture and a radiograph (Fig.1\&2)) of a thirty five year old female presenting with a slow growing painless lesion of the right parotid gland. The other images are of other patients with the same tumour. What are the important radiological features and what is your diagnosis?

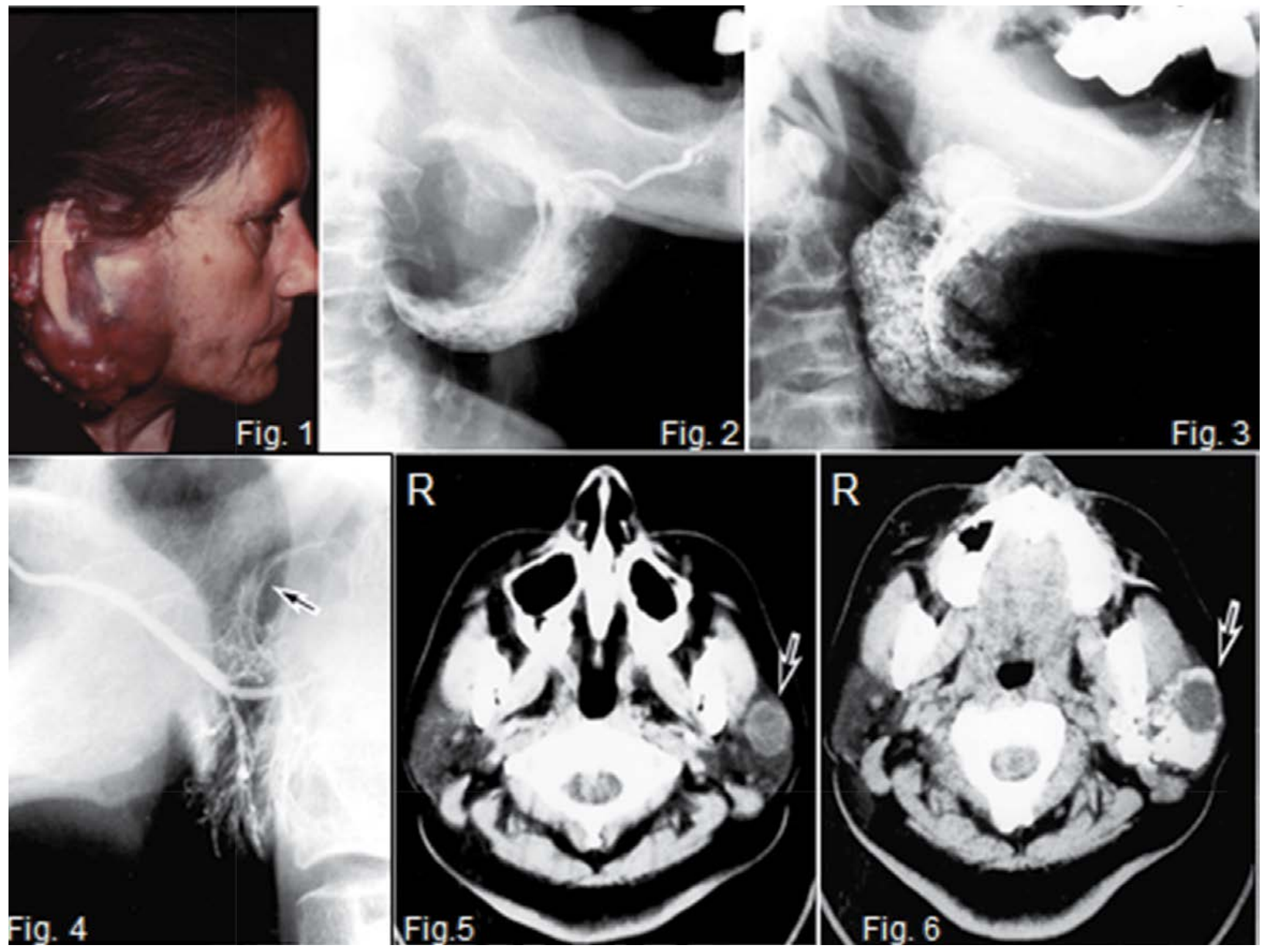

INTERPRETATION

Figures $1 \& 2$ are a case of a pleomorphic adenoma of the parotid gland affecting the right side. Pleomorphic adenoma, also known as a mixed tumour, is the most common benign tumour affecting salivary glands. It accounts for $60-70 \%$ of all salivary gland lesions. Growth of the pleomorphic adenoma is slow and painless. The onset of the disease is usually in the second to fifth decades of life. When a tumour exits in the secretory portion and is relatively large, it produces the typical sialographic appearance of the so-called "ball in hand" (Fig. 3). This finding is caused by a dislocation of and pressure on the duct resulting from a benign tumour with a capsule or pseudo capsule. The ducts appear to surround the tumour, which is accompanied by a filling defect in the gland parenchyma. Because of pressure by the tumour, the duct is extended, and the distance between furcations becomes longer. Interruption of the extended duct may also be present. Sialogram of pleomorphic adenoma of the left parotid gland (Fig. 4)

CJ Nortjé: BChD, PhD, ABOMR, DSc. Faculty of Dentistry, University of the Western Cape. E-mail: cnortje@uwc.ac.za shows dysfunction of the secondary ducts resulting from pressure of the tumour. Lateral view of the parotid sialogram shows the low density of the contrast medium (arrow). On CT and MR imaging pleomorphic adenoma appears as a round lesion with a distinct boundary line between it and the surrounding tissues. Sometimes its central part has a slightly lower density. The axial CT (Fig. 5 arrow) of a pleomorphic adenoma of the left parotid gland shows a round, encapsulated, wellcircumscribed lesion. Computed tomographic sialogram of the same patient confirms the position of the tumour, (Fig. 6 arrow). Therefore CT sialography is very effective for the diagnosis tumour localization (topographic diagnosis). On ultrasonography; internal echoes are absent or homogeneous and weak. The posterior echoes are enhanced. Scintigrams show areas of decreased radioactivity and correspond to the neoplasm. Differential diagnosis may include Adenolymphoma (Wharton tumour) and Lipoma.

\section{Reference}

1. Farman AG, Nortjé CJ \& Wood R E: Oral and Maxillofacial Imaging, 1st Ed, Mosby. St. Louis, Missouri 1993 pp 413-415. 